\title{
Childhood deaths in Down's syndrome. Survival curves and causes of death from a total population study in Queensland, Australia, 1976 to 1985
}

\begin{abstract}
JUDITH A BELL*, JOHN H PEARN†, AND DAVID FIRMAN
From * State Health Laboratory, Queensland Department of Health, PO Box 495, Brisbane, Queensland 4000; +Department of Child Health, Royal Children's Hospital, Herston, Brisbane, Queensland 4029; and $\ddagger$ Epidemiology and Prevention Unit, Queensland Department of Health, PO Box 48, Brisbane, Queensland 4001, Australia.
\end{abstract}

SUMMARY Data have been obtained from a total population study of diagnosed Down's syndrome cases born in Queensland between 1976 and 1985. Survival curves show a survival rate to one year of $87.4 \%$ and no significant differences in such patterns over the two five year periods of the study. Survival curves comparing maternal age at birth, sex of the infant, and locality of birth also indicate that early death is unrelated to any of these factors. Congenital heart disease and respiratory infection are the most common causes of infant death.

An accurate knowledge of survival in Down's syndrome is required for genetic counselling, for clinical management decisions, and for those with the responsibility of providing health care and support services for infants born with this condition.

From the point of view of couples at risk, family planning decisions (for example, spacing of conceptions, and decisions whether or not to embark on a future pregnancy) also require accurate information about longevity should such an affected child be born.

Attempts to estimate life expectancy for Down's syndrome have been undertaken in many studies. Penrose $^{1}$ in 1949 reported that the average life expectancy for Down's syndrome in 1929 was nine years and had risen to 12 to 15 years by 1947 . Similar findings were published by Brothers and Jago in 1954. ${ }^{2}$ Subsequent studies have documented average life expectancy estimated at the time of birth to be 16.2 years, ${ }^{3} 30.5$ years, ${ }^{4} 35$ years, ${ }^{56}$ and 50 years. $^{7}$ This wide disparity has resulted in part from several different methodological approaches. Some studies have included institutionalised cases only ${ }^{2}{ }^{4}$; the degree and nature of selection of index cases is indeterminate in others ${ }^{3}$; and some studies ${ }^{6}$ have undertaken analysis using a combination of raw data from different countries ${ }^{89}$ with expected differences

Received for publication 5 October 1988

Revised version accepted for publication 25 May 1989. in survival trends. It is general experience ${ }^{1-7}$ als that increased life expectancy in this condition is subject to significant secular trends. The vigour witt which neonatal surgical intervention for associated congenital malformations, especially congenital heart disease, has been performed obviously affects survival and has been subject to attitudinal and ethical changes. ${ }^{10-14}$

As recently as 1981 , an editorial in the British Medical Journal noted "If the child is one of the one quarter of newborns with Down's syndrome with congenital defects of the heart or other organs, then treatment may reasonably be withheld". ${ }^{15}$ By 1984 , even allowing for transatlantic differences, attitudes had changed perceptibly as noted in a major position statement published in the Journal of the American Medical Association: "Some infants with Down's syndrome born with a defect correctable by a surgical procedure with acceptable risks are sometimes denied the benefit of the procedure ... . there is a growing consensus in our society that life, even with handicaps, is preferable to death . . . most persons with Down's syndrome who survive infancy seem to lead reasonably happy lives, free of pain ... for this reason the care and treatment and all other rights that belong to normal infants should be standard for the person with Down's syndrome."16

In parallel with these significant variations in total life expectancy, large differences in survival in the first years of life have also been reported. This 
theme is particularly important in genetic counselling, where couples' decision making is influenced by such factors as survival rate in infancy and childhood, ${ }^{17}{ }^{18}$ should a Down's syndrome child be born. Current best estimates have indicated that parents can expect survival to the first birthday to exceed $80 \%^{7}{ }^{12} 19-23$ and two of these studies have shown that, even in those 20 to $30 \%$ of Down's syndrome cases born with a congenital heart defect, survival to the first birthday exceeds $75 \% .^{12} 23$

Diseases of the respiratory tract (pneumonia and bronchopneumonia) are the most commonly reported terminal causes of death in Down's syndrome, followed by deaths resulting from complications of congenital heart defects. ${ }^{2024-28}$ Because of (1) these wide differences in reported survival, (2) current secular trends and the factors influencing them, (3) changes in ethical attitudes to life support in Down's syndrome, and (4) anticipated changes in birth rates owing to increasing awareness of prenatal diagnosis, further total population surveys of unselected cases are needed. We report in this paper such a study from Queensland, Australia. This population has certain advantages as inadvertent case selection is reduced to a minimum. ${ }^{29}{ }^{30}$ Survival curves for the first decade of life are presented and analysed with regard to secular trends, maternal age, birth locality, and sex.

\section{Material and methods}

All cases of Down's syndrome livebirths notified to the Queensland Register of Chromosome Abnormalities $^{31}$ between 1976 and 1985 and the State Congenital Abnormalities Register since $1981^{32}$ have been included. Four hundred and twenty six cases have been identified, giving a population incidence of diagnosed cases of 1 in 880 livebirths (or 11.3 per 10000 livebirths). This rate is comparable with those reported for populations with relatively high ascertainment and similar demographic patterns (that is, sophisticated Western societies with similar mean family size and parity patterns). ${ }^{33-36}$

In such a total population study as this, there are potential methodological difficulties relating to ascertainment. ${ }^{11}$ Although data are collected from several sources, some cases of Down's syndrome may not have been recognised as such before death. Secondly, in the absence of consecutive newborn studies with appropriate follow up, there can be no certainty that all cases of Down's syndrome born within a defined demographic area are included. Cross referencing between the two Registers ${ }^{31} 32$ has shown that 20 cases (out of a total series of 426 cases) were not confirmed cytogenetically. We

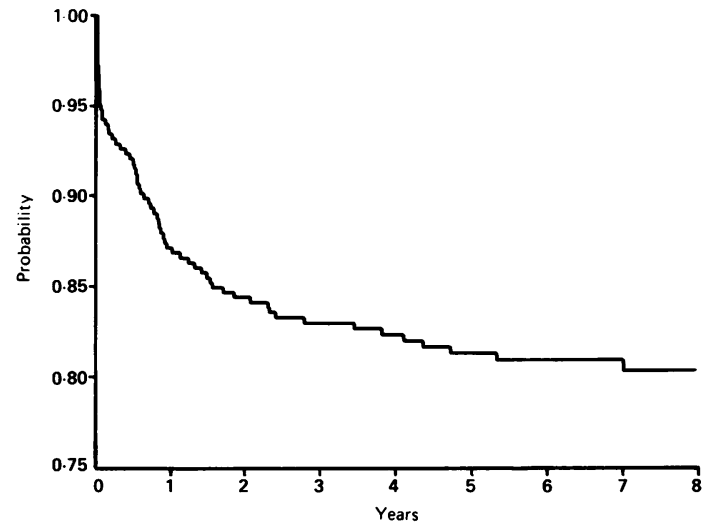

FIG 1 Down's syndrome survival curve. All cases diagnosed 1976 to 1985.

believe that this latter group may include some neonates diagnosed clinically who died before chromosome studies were instigated, a source of potential bias we believe is present in all series.

Three hundred and sixty-six cases $(86 \%)$ have been followed to the survey point (March 1988). Reasons for non-follow up of the remainder include adoptions ( 21 cases), those lost to follow up (19 cases), and cases notified only to the Congenital Malformations Register (20 cases).

Age at death, maternal age at birth, locality of birth, and cause of death have been supplied by the Queensland Registrar of Births, Deaths, and

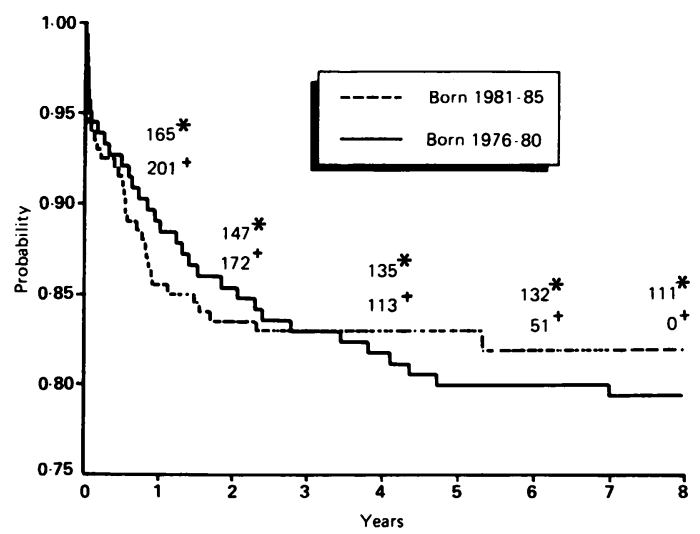

FIG 2 Survival curves for Down's syndrome, cases born 1976 to 1980 and 1981 to $1985 .{ }^{*}$ Number at risk of those born 1976 to 1980. + Number at risk of those born 1981 to 1985. 


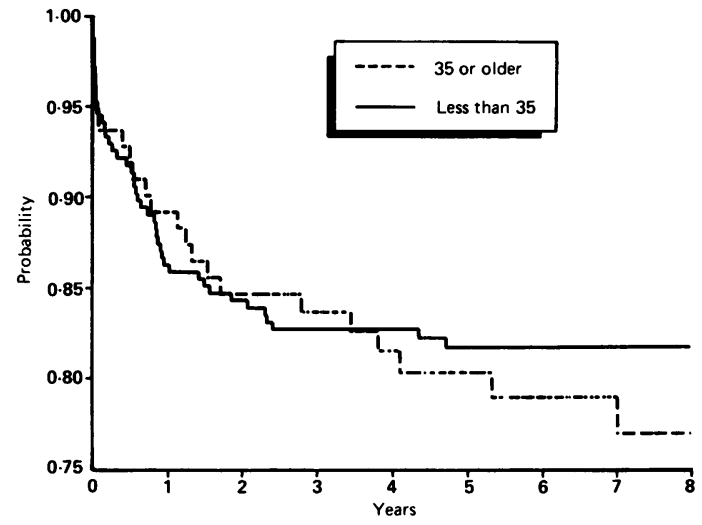

FIG 3 Survival curves for Down's syndrome by maternal age at birth.

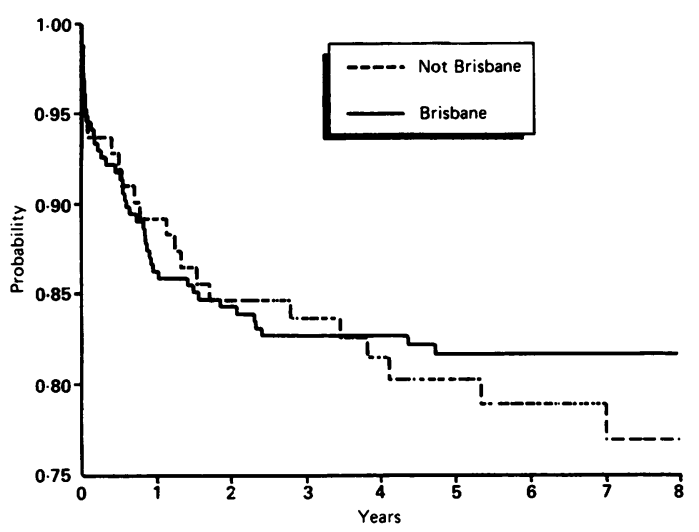

FIG 4 Survival curves for Down's syndrome by birth place of infant.

Marriages. Kaplan-Meier curves were calculated for all cases classified according to year of birth, maternal age, sex, and place of birth. Survival curves were tested for heterogeneity using the logrank test. ${ }^{37}$

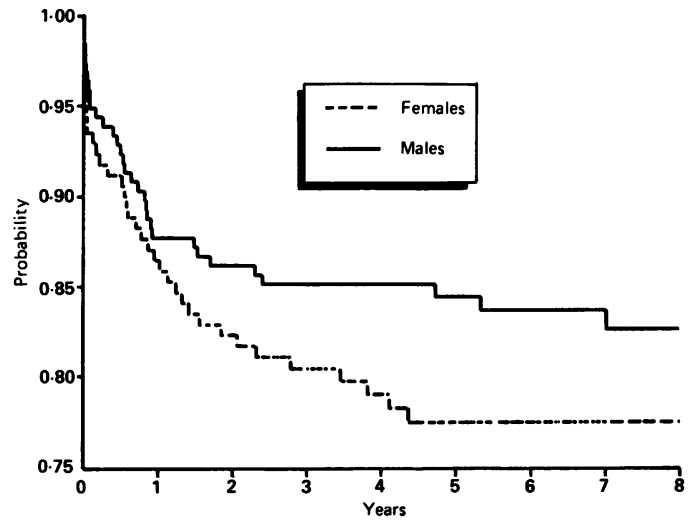

FIG 5 Survival curves for Down's syndrome by sex of infant.

\section{Results}

The deaths of 69 cases occurred within the survey period. Of these, 47 died before their first birthday giving an estimated probability of survival to one year of 0.87 (95\% confidence limits $0.84,0.91)$.

Cardiac anomalies were cited as a cause of deathg in 41 of the 69 deaths. Respiratory infection was documented as a contributing factor in 27 cases There were two deaths from leukaemia and no reports of any death through accident, drowning, violence, or the sudden infant death syndrome.

The overall survival curve is presented in fig 1 . All but seven deaths occurred before three years of age and no deaths were observed after seven years. As the cohort consisted of children born between 1976 and 1985, the length of follow up varied from 12 years down to three years for the youngest children.

Survival curves were plotted for cases classified by year of birth, maternal age, sex, and place of birth and are presented in figs 2 to 5 . Superimposed on the graph in fig 2 are the numbers in each birth cohort at risk at one, two, four, six, and eight years.

TABLE Analysis of Down's syndrome deaths: Queensland, Australia, 1976 to 1980.

\begin{tabular}{|c|c|c|c|c|c|c|c|}
\hline Classification & & No & Observed & Expected & Observed/expected & $x^{2}$ & $p$ \\
\hline Period & $\begin{array}{l}1976-80 \\
1981-85\end{array}$ & $\begin{array}{l}165 \\
201\end{array}$ & $\begin{array}{l}34 \\
35\end{array}$ & $\begin{array}{l}32 \cdot 64 \\
36 \cdot 36\end{array}$ & $\begin{array}{l}1.04 \\
0.96\end{array}$ & $0 \cdot 11$ & 0.74 \\
\hline Maternal age & $\begin{array}{l}<35 y \\
35+y\end{array}$ & $\begin{array}{l}255 \\
111\end{array}$ & $\begin{array}{l}46 \\
23\end{array}$ & $\begin{array}{l}48 \cdot 13 \\
20 \cdot 87\end{array}$ & $\begin{array}{l}0 \cdot 96 \\
1 \cdot 10\end{array}$ & $0 \cdot 31$ & 0.58 \\
\hline Place of birth & $\begin{array}{l}\text { Brisbane } \\
\text { Not Brisbane }\end{array}$ & $\begin{array}{l}123 \\
243\end{array}$ & $\begin{array}{l}23 \\
46\end{array}$ & $\begin{array}{l}23 \cdot 27 \\
45 \cdot 73\end{array}$ & $\begin{array}{l}0.99 \\
1.01\end{array}$ & 0.005 & 0.95 \\
\hline Sex & $\begin{array}{l}\text { Male } \\
\text { Female }\end{array}$ & $\begin{array}{l}196 \\
170\end{array}$ & $\begin{array}{l}32 \\
37\end{array}$ & $\begin{array}{l}37 \cdot 47 \\
31 \cdot 53\end{array}$ & $\begin{array}{l}0.85 \\
1 \cdot 17\end{array}$ & 1.75 & $0 \cdot 19$ \\
\hline
\end{tabular}


This is done to emphasise the relatively shorter period of follow up for the cohort born in 1981 to 1985.

The results of tests for heterogeneity from each of the four classifications of cases are summarised in the table. No significant differences were found for a type 1 error of $0 \cdot 05$.

\section{Discussion}

Survival rates to one year for Down's syndrome have been calculated for several populations and show significant increase over the last 40 years; published rates in the last two decades vary between $83.0 \%$ and $94.0 \% .^{7812} 19-23$ The survival rate to one year of $87.4 \%$ in the present study is consistent with these earlier estimates. In practice, if parents are planning a future pregnancy in the face of a risk of Down's syndrome (as in the case of older mothers), one is able to say that if such a child is born, there is a nine out of ten chance that the infant will survive. Studies of risk taking behaviour in the context of other genetic diseases have shown that parents are more willing to accept a genetic gamble if they know a child will not survive infancy. This study has not provided objective evidence for any increased survival, which might have been anticipated if ethical influences had protected Down's infants who would otherwise have died.

Although no significant differences were found for any classification of cases it must be noted that, as there were only relatively few deaths, the test for heterogeneity had power only to detect reasonably large differences in survival. For example, for two groups of equal size, the test had only a $80 \%$ chance of detecting a 2:1 difference in hazard rates. Nevertheless, the survival curves indicate little apparent difference between groups for each classification, especially as the vertical scale chosen tends to exaggerate any differences in survival history.

There was no evidence of any large difference in survival within the 10 year period and the data did not suggest any apparent difference. Two recently published studies which analysed their own data for secular trends showed differing results. Baird and Sadovnick ${ }^{23}$ could not find any difference in survival between each 10 year period of their 30 year study, either for the group as a whole or for those with or without congenital heart defects. Malone, ${ }^{12}$ however, when comparing data from the West Australian population from 1966 to 1976 and then between 1976 and 1984 found a significant improvement in Down's syndrome survival rates, particularly for those infants with congenital heart defects.

Elwood and Darragh, ${ }^{38}$ in a study of Down's syndrome in Northern Ireland, reported mortality among cases born to older mothers to be twice that for younger mothers. From our data, no significant difference could be found for survival related to maternal age at birth.

In a state the size of Queensland, with a population distribution such that many births occur some distance from a major medical centre, it seemed pertinent to ascertain whether survival of a neonate with Down's syndrome was at all dependent on locality of birth. Our results indicate that affected infants born outside the Brisbane metropolitan area are not apparently disadvantaged medically.

Some previous studies have indicated a higher mortality rate in females with Down's syndrome 3824 while others have shown no difference between male and female survival. ${ }^{7912} 1920$ Although our data showed a higher number of female deaths than would have been expected, these results were not significant. Of interest here are two studies which examine sex differences with respect to the presence (or absence) of congenital heart defects. ${ }^{10}{ }^{23}$ Both report a significantly higher proportion of female Down's syndrome cases with congenital heart defects, which may be a reason for the trend towards lower survival rates for females in some reports.

Survival of Down's syndrome infants with congenital heart disease, compared to those without it, has been shown in several studies to be significantly decreased. ${ }^{72023}$ This is confirmed in our study with congenital heart disease documented as the cause of death in $59.4 \%$ of all deaths. A recent Australian study, however, showed that, for their population, the presence of congenital heart disease is no longer a major determinant of poor outcome. ${ }^{12}$

These studies clearly show that, in current practice, a Down's syndrome infant has a very high chance of surviving infancy. This fact, combined with the relatively small effect prenatal diagnosis has in reducing the incidence, ${ }^{39}$ means that the prevalence of Down's syndrome in our population will increase. This has implications for those charged with the responsibility for providing life time care for such persons in the areas of health, welfare, and education.

We thank the Registrar General of Births, Deaths, and Marriages for providing data on each case, the Queensland Cytogenetic Group for permitting access to the Chromosome Registry and laboratory records, the Central Statistical Unit at the Queensland State Health Department for providing information on Down's syndrome cases notified to the Congenital Abnormality Register, and Professor Arthur Brownlea, School of Australian Environmental Studies, Griffith University, Queensland. 


\section{References}

1 Penrose LS. The incidence of mongolism in the general population. J Ment Sci 1949;95:685-8.

2 Brothers CRD, Jago GC. Report on the longevity and the causes of death in mongoloidism in the State of Victoria. J Ment Sci 1954;100:580-2.

${ }^{3}$ Collmann RD, Stoller A. Data on mongolism in Victoria, Australia: prevalence and life expectation. J Ment Defic Res 1965;7:60-8.

${ }^{4}$ Deaton JG. The mortality rate and causes of death among institutionalised mongols in Texas. J Ment Defic Res 1973;17: $117-22$.

5 Richards BW, Sylvester PE. Mortality trends in mental deficiency institutions. J Ment Defic Res 1969;13:276-92.

6 Jones MB. Years of life lost through Down's syndrome. J Med Genet 1979;16:379-83.

7 Masaki M, Higurashi M, Iijama K, et al. Mortality and survival for Down's syndrome in Japan. Am J Hum Genet 1981;33:629-39.

${ }^{8}$ Fabia J, Drolette M. Life tables up to age 10 for mongols with and without heart defect. J Ment Defic Res 1970;14:235-42.

9 Oster J, Mikkelsen M, Nielsen A. Mortality and life-table in Down's syndrome. Acta Paediatr Scand 1975;64:322-6.

${ }^{10}$ Murdoch JC. Congenital heart disease as a significant factor in the morbidity of children with Down's syndrome. J Ment Defic Res 1985;29:147-51.

11 Fryers T. Survival in Down's syndrome. J Ment Defic Res 1986;30:101-10.

12 Malone Q. Mortality and survival of the Down's syndrome population in Western Australia.J Ment Defic Res 1988;32:59-65.

13 Bull C, Rigby ML, Shinebourne EA. Should management of complete atrioventricular defect be influenced by coexistent Down syndrome? Lancet $1985 ; \mathrm{i}: 1147-8$.

14 Potts SR, Garstin WI. Neonatal duodenal obstruction with emphasis on cases with Down's syndrome. Ulster Med J 1986;55:147-50.

15 Editorial. Paediatricians and the law. Br Med J 1981;283: 1280

16 Smith GF, Diamond E, Lejeune J, et al. The rights of infants with Down's syndrome. JAMA 1984;251:229.

17 Pearn JH. Patient's subjective interpretation of risks offered in genetic counselling. J Med Genet 1973;10:129-33.

18 Pearn J. Decision-making and reproductive choice. In: Hsia YE, et al, eds. Counselling in genetics. Chap 10. New York: Alan R Liss, 1979:223-38.

19 Gallagher RP, Lowry RB. Longetivy in Down's syndrome in British Columbia. J Ment Defic Res 1975;19:157-63.

${ }^{20}$ Mulcahy MT. Down's syndrome in Western Australia: mortality and survival. Clin Genet 1979;16:103-8.

${ }^{21}$ Fryers T, Mackay RI. Down's syndrome: prevalence at birth, mortality and survival. A 17 year study. Early Hum Dev 1979;3:29-41.

22 Dupont A, Vaeth M, Videbech P. Mortality and life expectancy of Down's syndrome in Denmark. J Ment Defic Res 1986;30: 111-20.

${ }^{23}$ Baird PA, Sadovnik AD. Life expectancy in Down syndrome. J Pediatr 1987;110:849-54.

${ }^{24}$ Carter CO. A life-table for mongols with the causes of death. $J$ Ment Defic Res 1958;2:64-74.

${ }^{25}$ Mikkelsen M. Epidemiology of trisomy 21: population, periand antenatal data. Hum Genet 1981;2:211-26.

${ }^{26}$ Balarajan R, Donnan SPB, Adelstein AM. Mortality and cause of death in Down's syndrome. J Epidemiol Community Health 1982;36:127-9.

27 Thase ME. Longevity and mortality in Down's syndrome. J Ment Defic Res 1982;26:177-92.

${ }^{28}$ Chaney RH, Eyman RK, Miller CR. The relationship of congential heart disease and respiratory infection mortality in patients with Down's syndrome. J Ment Defic Res 1985;29:23-7.

29 Bell J, Pearn J, McCarthy C, et al. A total population study of diagnosed chromosome abnormalities in Queensland, Australia. Clin Genet 1982;22:49-56.

${ }^{30}$ Bell JA, Bell JR, Pearn JH. Diagnostic trends in childhood chromosome abnormalities and their implications. A total population eight-year survey from Queensland, Australia. Birth Defects 1987;23(1):307-14.

${ }^{31}$ Bell JA, Bowling FG, Pearn JH, et al. Register of chromosomal abnormalities in Queensland. Med J Aust 1983;2:186-9.

32 Queensland Department of Health. Central Statistical Unit. Queensland Congenital Abnormality Register, 1987.

${ }^{33}$ Hook EB. Down syndrome: its frequency in human populations and factors pertinent to variation in rates. In: de la Cruz FF, Gerald PS, eds. Trisomy 21 (Down syndrome) research perspectives. Baltimore: University Park Press, 1981:3-67.

34 Owens JR, Harris F, Walker S, et al. The incidence of Down's syndrome over a 19 year period with special reference to maternal age. J Med Genet 1983;20:90-3.

35 Nielsen J, Videbech P. Diagnosing of chromosome abnormalities in Denmark. Clin Genet 1984;26:422-8.

${ }^{36}$ National Perinatal Statistics Unit, University of Sydney. Congenital Malformations Monitoring Report, September 1986;22:9.

37 Peto R, Pike MC, Armitage NE, et al. Design and analysis of randomised clinical trials requiring prolonged observation of each patient. Br J Cancer 1977;35:1-39.

38 Elwood JH, Darragh PM. Prevalence of mongolism in Northern Ireland. J Ment Defic Res 1981;25:157-60.

39 Bell J, Hilden J, Bowling F, Pearn J, Brownlea A, Martin N. The impact of prenatal diagnosis on the occurrrence of chromosome abnormalities. Prenat Diagn 1986;6:1-11.

Correspondence to Dr J A Bell, Laboratory of Microbiology and Pathology, State Health Laboratory, 63 George Street, GPO Box 495, Brisbane, Queensland 4001, Australia. 